\title{
Factors Associated with Smokeless Tobacco Use among Pregnant Women in Rural Areas of the Southern Terai, Nepal
}

Jitendra Kumar Singh, ${ }^{1}$ Dilaram Acharya, ${ }^{2}$ Rajendra Kadel, ${ }^{3}$ Samaj Adhikari, ${ }^{4}$ Daniel Lombard, ${ }^{3}$ Sumitra Koirala, ${ }^{5}$ Rajan Paudel ${ }^{6}$

${ }^{1}$ Department of Community Medicine, Institute of Medical Sciences, Banaras Hindu University, India, ${ }^{2}$ Department of Community Medicine, Devdaha Medical College and Research Institute, Kathmandu University, Bhaluhi, Rupandehi, Nepal, ${ }^{3}$ Personal Social Services Research Unit, London School of Economics and Political Science, London, UK, ${ }^{4}$ Institute of Medicine, Kathmandu, Nepal, ${ }^{5}$ Department of Nursing, Sanjeevani College of Medical Sciences, Rupandehi, Nepal, 'Department of Community Medicine and Public Health, Institute of Medicine, Kathmandu, Nepal.

\section{ABSTRACT}

Background: Tobacco use among women during pregnancy leading to poor maternal and child health outcomes has been well documented. However, factors influencing use of smokeless tobacco in Nepal has not yet been well established. This study aims at exploring the factors related to smokeless tobacco use among pregnant women in rural southern Terai of Nepal.

Methods: A community-based cross-sectional study was performed at 52 wards within 6 Village Development Committee in Dhanusha district of Nepal. A total of 426 expectant mothers in their second trimester were selected using a multistage cluster sampling method. Descriptive and regression analyses were done to explore the factors that influence smokeless tobacco use.

Results: In a total of 426 pregnant mothers, one in five used tobacco in any form. Among the users, $13.4 \%$ used smokeless tobacco. Pregnant mothers who were smoking tobacco (AOR 6.01; 95\% CI (1.88-19.23), having alcohol consumption (AOR 3.86; 95\% CI (1.23-12.08), stressed (AOR 5.04; 95\% CI (1.81-14.03), non-vegetarian (AOR $3.31 ;(1.84-13.03)$, not attending regular mothers' group meetings (AOR 4.63; (1.41-15.19), and not-exposed to mass media (AOR 5.02; (1.89-13.33) were significantly associated with smokeless tobacco use. Similarly, mothers of age group 20-34 years, dalit, aadibasi and janajati, hill origin, no education and primary education were more likely to use smokeless tobacco than their counterparts.

Conclusions: Factors such as smoking tobacco, alcohol consumption, stress, and poor education were found to be significantly associated with smokeless tobacco use among pregnant women in southern Terai of Nepal. This requires an immediate attention develop an effective strategy to prevent and control smokeless tobacco use among pregnant women in southern Terai of Nepal.

Keywords: Nepal; pregnant women; smokeless tobacco.

\section{INTRODUCTION}

Tobacco use is one of the major public health threats worldwide. ${ }^{1}$ In 2010, smokeless tobacco use was attributable to 1.7 million Disability Adjusted Life Years(DALYs) lost and over 62,000 deaths in 113 countries, of which $85 \%$ of this burden was in South East Asian countries. ${ }^{2}$
Tobacco consumption among pregnant women have several adverse consequences on maternal and child health. ${ }^{3}$ Several studies among pregnant women from Nepal and India showed that illiteracy, urban residence, manual occupation, husband's smoking habit, being divorced, and Terai heritage were associated with increased risk of smokeless tobacco use..$^{4-7}$ 
Smokeless tobacco is a form of tobacco which is consumed without burning it through the mouth or nose. Some common smokeless tobacco products available in Nepal are "gutka”, "pan masala”, "betel-quid”, "khaini or surti", "zarda", snuff and "gul”. Our study aimed to explore the factors that influence smokeless tobacco use among pregnant women in rural southern Terai of Nepal.

\section{METHODS}

A cross-sectional survey was conducted in Dhanusha district of Nepal between July and September 2015. Dhanusha is one of the 75 districts of Nepal, situated in the southern Terai. This district is, administratively, comprised of one municipality and 101 Village Development Committees (VDCs), which is further divided into smaller administrative units called wards. ${ }^{8}$

This study employed multi-stage cluster sampling. First of all, two primary health care facilities (consisting of one primary health care centre and one health post) were selected purposively, which consisted of 12 VDCs. We selected these areas because there were no other health-related organizations to support government's tobacco control services among pregnant women. Furthermore, no research has been conducted yet relating to this field in those study sites.

Each health care facility consisted of six VDCs and the population in each VDC ranges from 3,500 to $19,000 .^{9}$ Secondly, these six VDCs from each health facility catchment area were then stratified into three groups on the basis of population size $(<5000,5000-10000$, and $>10000) .{ }^{8,9}$ Then, one VDC was selected from each stratum in both health facility areas using simple random sampling method, which gave six VDCs in total for our study. These six VDCs consisted of 54 wards, we called here as study cluster. We excluded two of these clusters because these were situated in a town area. Hence, 52 clusters were included in this study. Finally, complete enumeration of all households with pregnant women between 13-28 weeks of gestation in the selected clusters was carried out for our study. We identified 453 participants eligible for the study, with the help from health facility staff and female community health volunteers (FCHVs). Twenty seven did not respond to the study that left 426 participants for the study (figure 1).

Participants who were women between 15 to 45 years of age, pregnant with gestation period between 13 to 28 weeks, living in rural areas, no serious health problem and willing to participate in the study were eligible for this study.

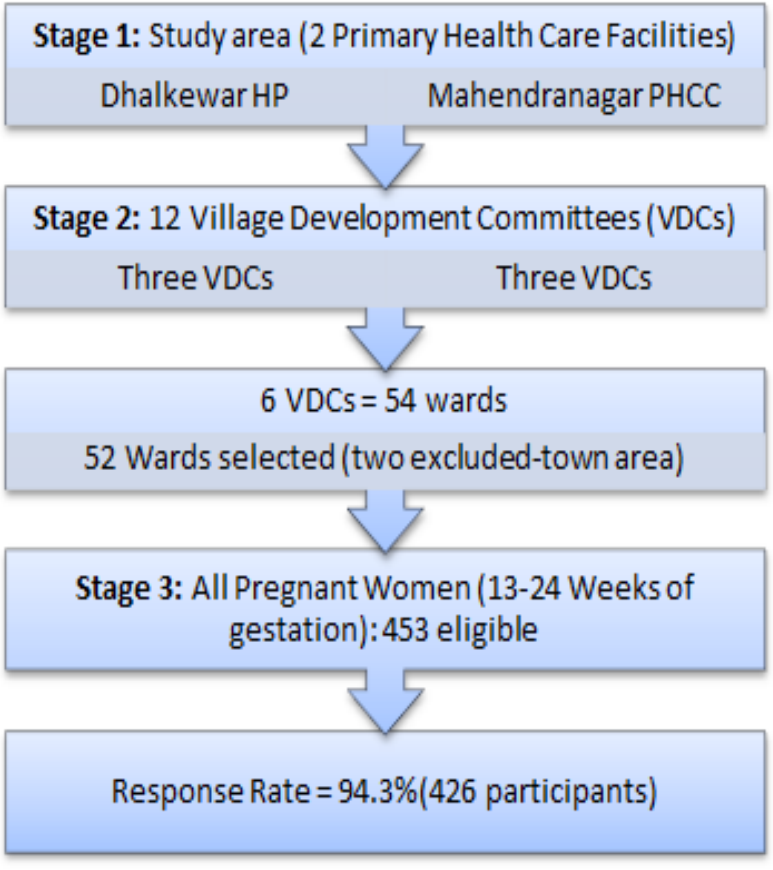

\section{Figure 1. Sampling Strategy}

Data were collected from six nursing students (research assistants) using a structured questionnaire during faceto-face interviews. All research assistants were trained before we sent them for data collection. The English version of the questionnaire was prepared, checked and pre-tested in $10 \%$ of the estimated sample in Kishannagar and Auragi VDCs of Mahottari district and necessary changes were made as needed. The questionnaire was then translated into Nepali and back into English by the researchers to ensure that the meanings of the questions were not modified. The questionnaire consisted of three parts: i) use of tobacco by pregnant women ii) respondents baseline characteristics, and iii) individual and obstetric characteristics, and maternal medical conditions.

The main outcome variable of this study was smokeless tobacco use among pregnant women. Independent variables included were: socio-demographic, occupational, maternal factors, participation and wealth index categorised as lower, second, middle, fourth, and highest. Altogether 29 household amenities/assets were considered in this study that were utilized by the family. Wealth Index was calculated by using Principal Component Analysis (PCA) using the same methodology as the Nepal Adolescent and Youth Survey. ${ }^{10}$ Maternal factors such as age, caste/ethnicity, origin, maternal and their husband's education, dietary habits, dietary variety, additional food consumption (one extra meal than regular meal required for adult woman), smoking, 
alcohol consumption, spousal violence, stress, exposure to mass media such as radio, television, printed media and hoarding board and attendance to mother's group meetings.

The socio-demographic characteristics such as religion, origin, maternal occupation, maternal education, husband's education, and husband's occupation were adapted from Nepal demographic and population health survey 2011. ${ }^{11}$ Caste/ethnicity was based on the caste system in Nepal, and was divided into three major groups based on available literature and similarities between the caste/ethnic groups: disadvantaged/dalit, disadvantaged/aadibasi/janajati, and advantaged/ upper caste (Brahmin and Chhetri). ${ }^{12,13}$ Dietary diversity was coded into three categories: low, medium, and high on the basis of food items consumed by pregnant women from 16 food groups as recommended by FAO. ${ }^{14}$ The consumption of food from $\leq 3$ food groups, 4-5 food groups, and $\geq 6$ food groups was considered as low, medium and high dietary diversity respectively. 14,15 Spousal violence was defined as any experience of physical, sexual, verbal, and psychological harm or suffering among pregnant women occurring in public or private life adapted from NDHS 2011. ${ }^{12}$

Stress was measured by the General Health Questionnaire (GHQ-12), validated instrument (sensitivity: $85 \%$ and specificity: $79 \%$ ) to measure a minor psychiatric disorders in many countries and translated into different languages, including Nepali. ${ }^{16-18}$ Information on attendance to a mothers' group meeting was categorized as attended and not attended. Exposure to any of the mass media (either printed or electronic) was categorized as exposed and not exposed during past three months.

All completed questionnaires were checked for completeness and consistency and verified on the same day. The data were then entered into Epi Data 3.1 Software. All the data files were checked and cleaned before analysis. The analysis of the data was carried out using SPSS version 20 for windows. Univariate analysis was used to describe the distribution of sample by use of smokeless tobacco during pregnancy. An association of various factors with the use of smokeless tobacco during pregnancy was analyzed using the chi-square test in bivariate analyses. Multivariable logistic regression model was used to assess the independent association between use of smokeless tobacco during pregnancy and maternal socio-demographic characteristics. Factors which were significant $(p<0.05)$ in bivariate analysis were selected for multivariable analysis and adjusted odds ratios (OR) and 95\% confidence intervals were obtained.

Ethical approval for the study was obtained from the Nepal Health Research Council, Nepal as well as the ethics committee of the Institute of Medical Sciences, Banaras Hindu University, India (approval no: ECR/526/ Inst/UP/2014 Dt.31.1.14) and District Public Health Office, Dhanusha, Nepal. The objectives, benefits and harms of the study was explained to the participants and their partner. Then informed consent was taken from them before taking interviews by the research assistants. We carried out this study in full compliance with national Ethical Guidelines for Health Research in Nepal and Standard Operating Procedures 2011.

\section{RESULTS}

Table 1 shows the current status of tobacco use among pregnant women. A total of $21.4 \%$ respondents reported the use of tobacco in any form, among them $13.4 \%$ used smokeless tobacco. Fifty-three percent of smokeless tobacco users used it 1-3 times a day and $25 \%$ of them used it once daily, while the remainder used it for more than 3 times a day.

Table 1. Pattern and frequency of tobacco use among pregnant women.

\begin{tabular}{|llc|}
\hline Variables & $\begin{array}{l}\text { Number } \\
(\mathbf{N}=426)\end{array}$ & Percentage \\
\hline Use of tobacco (any form) & 91 & 21.4 \\
\hline Smokes cigarettes* & 49 & 11.5 \\
\hline Smokes pipe* & 7 & 1.6 \\
\hline Smokes bidi* & 25 & 5.8 \\
\hline Smokeless tobacco* & 57 & 13.4 \\
\hline $\begin{array}{l}\text { Frequency of smokeless tobacco consumption } \\
\text { (n=57) }\end{array}$ & 14 & 24.5 \\
\hline Less than 1/day & 30 & 52.6 \\
\hline 1-3 times/day & 13 & 22.8 \\
\hline more than 3 times /day & & \\
\hline
\end{tabular}

*Multiple Responses

The socio-demographic characteristics of the study participants are shown in Table 2. Results from the study showed that smokeless tobacco use was significantly associated with age, ethnicity, birth origin, education levels, woman's occupation, and household wealth index.

Table 3 demonstrates the personal history associated with smokeless tobacco use. The findings showed that smokeless tobacco use was strongly associated with the participant's personal and obstetric history, such as 
Factor Associated with Smokeless Tobacco Use among Pregnant Women

\begin{tabular}{|c|c|c|c|c|}
\hline \multirow[t]{2}{*}{ Variable } & \multirow{2}{*}{$\begin{array}{l}\text { Total } \\
\text { n (\%) }\end{array}$} & \multicolumn{2}{|c|}{ Use of smokeless tobacco } & \multirow[t]{2}{*}{$\mathrm{p}$-value } \\
\hline & & Yes $(n=57)(\%)$ & $\operatorname{No}(n=369(\%)$ & \\
\hline \multicolumn{5}{|l|}{ Age (years) } \\
\hline$<20$ & $102(23.9)$ & $14(13.7)$ & $88(86.3)$ & 0.001 \\
\hline $20-34$ & $290(68.1)$ & $27(9.3)$ & 263(90.7) & \\
\hline $35-45$ & $34(8.0)$ & $16(47.1)$ & $18(53.9)$ & \\
\hline \multicolumn{5}{|l|}{ Caste/ethnicity } \\
\hline Dalit & $71(16.7)$ & $21(29.6)$ & $50(70.4)$ & $<0.0001$ \\
\hline Adibasi/janajati & $91(21.4)$ & $22(24.2)$ & $69(75.8)$ & \\
\hline Upper caste group & $264(62.0)$ & $14(5.3)$ & $250(94.7)$ & \\
\hline \multicolumn{5}{|l|}{ Religion } \\
\hline Hindu & $391(91.8)$ & $49(12.5)$ & $342(87.5)$ & 0.086 \\
\hline Muslim and Buddhist & $35(8.2)$ & $8(22.9)$ & $27(77.1)$ & \\
\hline \multicolumn{5}{|l|}{ Women's education } \\
\hline No education(illiterate) & $108(25.4)$ & $33(30.5)$ & $75(69.5)$ & $<0.0001$ \\
\hline $\begin{array}{l}\text { Primary ( } 1 \text { to } 5 \text { years of } \\
\text { schooling) }\end{array}$ & $149(35.0)$ & $12(8.0)$ & $137(92.0)$ & \\
\hline $\begin{array}{l}\text { Secondary }(6-10 \text { years of } \\
\text { schooling) }\end{array}$ & $79(18.5)$ & $7(8.9)$ & $72(91.1)$ & \\
\hline $\begin{array}{l}\text { Higher(Higher than } 10 \text { years of } \\
\text { schooling) }\end{array}$ & $90(21.1)$ & $5(5.6)$ & $85(94.4)$ & \\
\hline \multicolumn{5}{|l|}{ Husband's education } \\
\hline No education(illiterate) & $64(15.0)$ & $20(31.2)$ & $44(68.8)$ & $<0.0001$ \\
\hline $\begin{array}{l}\text { Primary ( } 1 \text { to } 5 \text { years of } \\
\text { schooling) }\end{array}$ & $131(30.8)$ & $12(9.2)$ & $119(90.8)$ & \\
\hline $\begin{array}{l}\text { Secondary }(6-10 \text { years of } \\
\text { schooling) }\end{array}$ & $91(21.36)$ & $9(9.9)$ & $82(90.1)$ & \\
\hline $\begin{array}{l}\text { Higher(Higher than } 10 \text { years of } \\
\text { schooling) }\end{array}$ & $140(32.9)$ & $16(11.4)$ & $124(88.6)$ & \\
\hline \multicolumn{5}{|l|}{ Women's occupation } \\
\hline Non agriculture & $292(68.5)$ & $30(10.3)$ & $262(89.7)$ & 0.005 \\
\hline Agriculture & $134(31.5)$ & $27(20.1)$ & $107(79.9)$ & \\
\hline \multicolumn{5}{|l|}{ Husband's occupation } \\
\hline Non agriculture & $280(71.1)$ & $35(12.5)$ & $245(87.5)$ & 0.082 \\
\hline Agriculture & $146(34.3)$ & $22(15.0)$ & $124(85.0)$ & \\
\hline \multicolumn{5}{|l|}{ Wealth index } \\
\hline Lower & $124(29.1)$ & $28(22.6)$ & $96(77.4)$ & 0.011 \\
\hline Second & $100(23.5)$ & $10(10.0)$ & $90(90.0)$ & \\
\hline Middle & $84(19.7)$ & $9(10.7)$ & $75(89.3)$ & \\
\hline Fourth & $61(14.3)$ & $5(8.2)$ & $56(91.8)$ & \\
\hline Highest & $57(13.4)$ & $5(8.8)$ & $52(91.2)$ & \\
\hline Total & 426 & 57 & 369 & \\
\hline
\end{tabular}

dietary habits, smoking, alcohol consumption, spousal The results of multiple logistic regression analyses are violence, stress, and mothers' group meetings and mass media exposure. shown in Table 4. Pregnant women from age group 20-34 years were more likely to use smokeless tobacco (AOR 4.2; 95\% Cl (1.3-14.2)) than women in their below 20 . 
Factor Associated with Smokeless Tobacco Use among Pregnant Women

\begin{tabular}{|c|c|c|c|c|}
\hline \multirow[t]{2}{*}{ Variable } & \multirow{2}{*}{$\begin{array}{l}\text { Total } \\
\mathrm{N}=426(\%)\end{array}$} & \multicolumn{2}{|c|}{ Use of smokeless tobacco } & \multirow[t]{2}{*}{$\mathrm{p}$-value } \\
\hline & & Yes $(n=57)(\%)$ & No $(n=369)(\%)$ & \\
\hline \multicolumn{5}{|l|}{ Dietary habits } \\
\hline Non Vegetarian & $335(78.64)$ & $51(15.2)$ & $284(84.8)$ & 0.032 \\
\hline Vegetarian & $91(21.36)$ & $6(6.6)$ & $85(93.4)$ & \\
\hline \multicolumn{5}{|l|}{ Smoking } \\
\hline No & $383(90.15)$ & $43(11.2)$ & $340(88.8)$ & 0.000 \\
\hline Yes & $43(9.85)$ & $14(32.6)$ & $29(67.4)$ & \\
\hline \multicolumn{5}{|c|}{ Alcohol consumption } \\
\hline No & $369(86.62)$ & $41(11.1)$ & $328(88.9)$ & 0.000 \\
\hline Yes & $57(13.38)$ & $16(28.1)$ & $41(71.9)$ & \\
\hline \multicolumn{5}{|c|}{ Spousal Violence } \\
\hline No & $303(71.13)$ & $31(10.2)$ & $273(89.8)$ & 0.002 \\
\hline Yes & $123(28.87)$ & $26(21.3)$ & $96(78.7)$ & \\
\hline \multicolumn{5}{|l|}{ Stress } \\
\hline No & $272(63.85)$ & $29(10.7)$ & $243(89.3)$ & 0.028 \\
\hline Yes & $154(36.15)$ & $28(18.2)$ & $126(81.8)$ & \\
\hline \multicolumn{5}{|c|}{ Mother's group meeting } \\
\hline Not attended & $320(75.1)$ & $50(15.6)$ & $270(84.4)$ & 0.018 \\
\hline Attended & $106(24.9)$ & $7(6.6)$ & $99(93.4)$ & \\
\hline \multicolumn{5}{|l|}{ Media exposure } \\
\hline No & $109(25.59)$ & $33(30.3)$ & $76(69.7)$ & 0.000 \\
\hline Yes & $317(74.41)$ & $24(7.6)$ & $293(92.4)$ & \\
\hline Total & 426 & 57 & 369 & \\
\hline
\end{tabular}

Expectant mother from dalit (AOR 3.9; 95\% Cl (1.113.8)) and aadibasi/ janajati(AOR 3.1; $95 \% \mathrm{Cl}(1.2-19.6)$ ) group were more likely to use smokeless tobacco than upper caste group. Similarly, participants from hill origin (AOR 3.8; 95\% Cl (1.6-9.2)) were more likely to use smokeless tobacco than Terai origin. Respondents with no education (AOR 9.6; 95\% Cl (2.5-32.7)) and primary education (AOR 4.5; 95\% Cl (1.1-17.7)) were more likely to use smokeless tobacco than higher education group.

Likewise, non-vegetarian (AOR 3.3; 95\% Cl (1.813.0)), smokers (AOR 6.0; 95\% Cl (1.9-19.2)), alcohol consumption group (AOR 3.9; $95 \% \mathrm{Cl}(1.2-12.0))$, and stressed women (AOR 5.0; $95 \% \mathrm{Cl}(1.8-14.0)$ ) were more likely, respectively, to use smokeless tobacco. Furthermore, pregnant women who were not attending regular mothers' group meetings (AOR 4.6; 95\% Cl (1.4-15.2)), and those who were not exposed to mass media (AOR 5.0; 95\% Cl (1.9-13.3)) were more likely, respectively, to use smokeless tobacco.
Table 4. Multiple logistic regression model for factors of antenatal addiction among rural women.

\begin{tabular}{lll|}
\hline Characteristics & $\begin{array}{l}\text { Crude OR } \\
(95 \% \mathrm{CI})\end{array}$ & $\begin{array}{l}\text { Adjusted OR } \\
(95 \% \mathrm{CI})\end{array}$ \\
\hline $\begin{array}{l}\text { Age (years) } \\
<20\end{array}$ & 1 & 1 \\
\hline $20-34$ & $2.19(0.9-4.9)$ & $4.6(1.3-15.5)$ \\
\hline $35-45$ & $3.0(1.5-6.0)$ & $1.66(0.6-4.9)$ \\
\hline Caste/ethnicity & & \\
\hline Upper Caste & 1 & 1 \\
\hline Adibasi/janajati & $5.7(2.8-11.7)$ & $3.1(1.2-19.6)$ \\
\hline $\begin{array}{l}\text { Dalit } \\
\text { Birth origin }\end{array}$ & $7.5(3.6-15.7)$ & $3.9(1.1-13.8)$ \\
\hline Terai & 1 & 1 \\
\hline Hill & $2.4(1.4-4.3)$ & $3.9(1.6-9.2)$ \\
\hline Participant's education & \\
\hline Higher & 1 & 1 \\
\hline Secondary & $1.6(0.5-5.4)$ & $2.6(0.8-7.6)$ \\
\hline Primary & $1.5(0.5-4.4)$ & $4.5(1.1-17.7)$ \\
\hline
\end{tabular}




\begin{tabular}{|c|c|c|}
\hline No education & $7.5(2.8-20.1)$ & $9.6(2.5-32.7)$ \\
\hline \multicolumn{3}{|c|}{ Husband's education } \\
\hline Higher & 1 & 1 \\
\hline Secondary & $0.8(0.3-2.0)$ & $1.7(0.5-5.7)$ \\
\hline Primary & $0.78(0.3-1.7)$ & $0.8(0.2-3.3)$ \\
\hline No education & $3.5(1.7-7.4)$ & $2.9(0.7-11.4)$ \\
\hline \multicolumn{3}{|l|}{ Dietary habit } \\
\hline Vegetarian & 1 & 1 \\
\hline Non-vegetarian & $2.5(1.0-6.1)$ & $3.3(1.8-13.0)$ \\
\hline \multicolumn{3}{|l|}{ Smoking } \\
\hline No & 1 & 1 \\
\hline Yes & $3.8(1.9-7.8)$ & $6.0(1.9-19.2)$ \\
\hline \multicolumn{3}{|c|}{ Alcohol consumption } \\
\hline No & 1 & 1 \\
\hline Yes & $\begin{array}{l}3.12 \quad(1.60- \\
6.05)\end{array}$ & $\begin{array}{l}3.86 \\
12.08)\end{array}$ \\
\hline \multicolumn{3}{|c|}{ Spousal violence } \\
\hline No & 1 & 1 \\
\hline Yes & $2.4(1.3-4.2)$ & $2.4(0.9-6.4)$ \\
\hline \multicolumn{3}{|l|}{ Stress } \\
\hline No & 1 & 1 \\
\hline Yes & $1.8(1.0-3.3)$ & $5.04(1.8-14.0)$ \\
\hline \multicolumn{3}{|c|}{ Mother's group meeting } \\
\hline Attended & 1 & 1 \\
\hline Not Attended & $2.6(1.1-6.0)$ & $4.6(1.4-15.2)$ \\
\hline \multicolumn{3}{|c|}{ Mass media exposure } \\
\hline Yes & 1 & 1 \\
\hline No & $5.3(2.9-9.5)$ & $5.0(1.9-13.3)$ \\
\hline
\end{tabular}

\section{DISCUSSION}

This study reveals that the prevalence of smokeless tobacco use among pregnant women in this region is $13.4 \%$, which is higher than national, ${ }^{19}$ and South Asian countries' average. ${ }^{20}$ This could be due to socioeconomic and cultural factors associated with smokeless tobacco use in rural areas. It is evident from the study that caste/ethnicity, birth origin, women's education, dietary habit, alcohol consumption, stress, attendance in mothers' group meetings, and exposure to mass media are risk factors for smokeless tobacco use among pregnant women in Nepal.

The ethnicity is an important predictor of smokeless tobacco use among pregnant women in our study. Those belonging to disadvantaged caste/ethnicity are more likely to consume smokeless tobacco compared to advantaged caste group women. This is consistent with studies from India, Canada and Australia and other countries. ${ }^{21-23}$ The higher rate of smokeless tobacco use among disadvantaged group could be due to less awareness of negative maternal and child health consequences of tobacco consumption.

Interestingly, pregnant women from hill origin are more likely to use smokeless tobacco. This could be due to free access and social acceptance of smokeless tobacco than smoking cigarette among women in hill area. Smokeless tobacco use in women is often more socially acceptable than tobacco smoking. ${ }^{24}$ Tobacco prevention strategies should focus on ethnic differences and cultural practices along with enforcement of laws and regulation in this regard.

Similarly, uneducated expectant mothers in our study are more likely to consume smokeless tobacco compared to educated group. The study findings concur with previous studies conducted in Bangladesh, Canada, and Nepal. 22,25,26 Several studies showed that educated women were more aware of health hazards of smokeless tobacco use during pregnancy and there was lower degree of family acceptance for tobacco use in the educated family compared to uneducated family. ${ }^{27-30}$

Our findings show that pregnant women who are vegetarian, participated in mothers' group meetings, and exposed to mass media are less likely to consume smokeless tobacco. Vegetarians could be absolute in their dietary habit and even some vegetarians are bound culturally, that is, they are restricted by the societies to get involved in unhealthy behaviour of smokeless tobacco use. Expectant mothers who are participated in mothers' group meetings and exposed to mass media could be more aware of the detrimental effect of smokeless tobacco. Studies based in India and SubSaharan Africa also revealed the positive impact of mass media on tobacco consumption. ${ }^{31,32}$ Furthermore, our study shows that women in a stress situation are more likely to consume smokeless tobacco compared to unstressed. This reflects the findings of an experimental study, ${ }^{33}$ highlighting the direct relation between stress level and tobacco consumption, and also women at a high stress level believe that smokeless tobacco consumption may temporarily reduce their work-or family-related stress.

There are number of limitations in this study: first, the status of smokeless tobacco use was self-reported which may be likely to have missed information. ${ }^{34}$ Second, this study lacks the effect of smokeless tobacco use on maternal and child health outcome as the data were collected for one cross-sectional point. Third, due to smaller sample size, the study findings lack its 
generalizability.

\section{CONCLUSIONS}

Low education, hill origin, disadvantaged ethnic groups, a habit of smoking and alcohol consumption, non-vegetarian diet, having high levels of stress, a lack of exposure to mass media, and non-attendance to mothers' group meetings are strongly associated with smokeless tobacco use. This signifies the need of formulation and implementation of effective strategies to prevent and control smokeless tobacco use for the overall improvement of maternal health and birth outcomes in southern Terai of Nepal

\section{ACKNOWLEDGEMENTS}

We would like to thank to our research assistants as well as all respondents for their kind cooperation during this study. We are grateful to all academicians of Institute of Medical Sciences, Banarus Hindu University, India for their academic guidance and support in this study.

\section{REFERENCES}

1. Forouzanfar $\mathrm{MH}$, Afshin A, Alexander LT, Anderson HR, Bhutta ZA, Biryukov S, et al. Global, regional, and national comparative risk assessment of 79 behavioural, environmental and occupational, and metabolic risks or clusters of risks, 1990-2015: a systematic analysis for the Global Burden of Disease Study 2015. Lancet. 2016;388(10053):1659-724. [PubMed]

2. Siddiqi K, Shah S, Abbas SM, Vidyasagaran A, Jawad M, Dogar O, et al. Global burden of disease due to smokeless tobacco consumption in adults: analysis of data from 113 countries. BMC Med. 2015;13(1):194. [PubMed]

3. Rogers JM. Tobacco and pregnancy. Reprod Toxicol.2009;28(2):152-60. [PubMed]

4. Nair S, Schensul JJ, Begum S, Pednekar MS, Oncken C, Bilgi SM, et al. Use of smokeless tobacco by Indian women aged 18-40 years during pregnancy and reproductive years. PLoS One. 2015;10(3):e0119814. [PubMed]

5. Mishra GA, Kulkarni SV, Gupta SD, Shastri SS. Smokeless tobacco use in Urban Indian women: Prevalence and predictors. Indian J Med Paediatr Oncol. 2015 JulSep;36(3):176-82. [PubMed]

6. Aryal UR, Bhatta DN, Shrestha N, Gautam A. Assessment of nicotine dependence among smokers in Nepal: a community based cross-sectional study. Tob Induc Dis.
2015;13(1):26. [PubMed]

7. Khanal V, Adhikari M, Karki S. Social determinants of tobacco consumption among Nepalese men: findings from Nepal Demographic and Health Survey 2011. Harm Reduct J. 2013;10:40. [PubMed]

8. District Health Profile of Dhanusha N. District Health Office, Dhanusha, Ministry of Health and Population In: District Health Office D, editor. Dhanusha, Nepal;2013.

9. District Development Committee Dhanusha. District Profile of Dhanusha District Development Committee. Janakpur, Nepal: District Development Committee Dhanusha; 2012.

10. Ministry of Health and Population.. Nepal Adolescents and Youth Survey. Kathmandu, Nepal:Ministry of Health and Population; 2012.

11. Ministry of Health and Population, New ERA, ICF International. Nepal Demographic and Health Survey 2011. Kathmandu, Nepal and Calverton, Maryland, U.S.A.: Ministry of Health and Population, New ERA and ICF International; 2012.

12. Khanal V, Adhikari M, Sauer K, Zhao Y. Factors associated with the introduction of prelacteal feeds in Nepal: findings from the Nepal Demographic and Health Survey 2011. Int Breastfeed J. 2013;8(1):9. [PubMed]

13. Acharya D, Khanal V, Singh JK, Adhikari M, Gautam S. Impact of mass media on the utilization of antenatal care services among women of rural community in Nepal. BMC Res Notes. 2015;8(1):345. [PubMed]

14. FAO. Dietary diversity questionnaire. FAO/Nutrition and Consumer Protection Division; 2007.

15. Savy M, Martin-Prével Y, Sawadogo P, Kameli Y, Delpeuch F. Use of variety/diversity scores for diet quality measurement: relation with nutritional status of women in a rural area in Burkina Faso. Eur J Clin Nutr. 2005;59(5):703-16.[PubMed]

16. Marri JJ, Williams P. A comparison of the validity of two psychiatric screening questionnaires (GHQ-12 and SRQ20) in Brazil, using Relative Operating Characteristic (ROC) analysis. Psychol Med. 1985;15(3):651-9. [PubMed]

17. Wisborg K, Barklin A, Hedegaard M, Henriksen TB. Psychological stress during pregnancy and stillbirth: prospective study. BJOG. 2008;115(7):882-5. [PubMed]

18. Kohrt BA.Vulnerable social groups in postconflict settings: a mixed methods policy analysis and epidemiology study 
of caste and psychological morbidity in Nepal. Interv. 2009;7(3):239-64.

19. Aryal K, Neupane S, Mehata S, Vaidya A, Singh S, Paulin F, et al. Non Communicable Diseases Risk Factors: STEPS Survey Nepal 2013. Kathmandu: GoN/MoHP, NHRC \& WHO;2014.

20. Caleyachetty R, Tait CA, Kengne AP, Corvalan C, Uauy R, Echouffo-Tcheugui JB. Tobacco use in pregnant women: analysis of data from Demographic and Health Surveys from 54 low-income and middle-income countries. Lancet Glob Health. 2014;2(9):e513-20. [PubMed]

21. Gupta PC, Subramoney S. Smokeless tobacco use and risk of stillbirth: a cohort study in Mumbai, India. Epidemiology. 2006;17(1):47-51. [PubMed]

22. Heaman MI, Chalmers K. Prevalence and correlates of smoking during pregnancy: a comparison of aboriginal and non-aboriginal women in Manitoba. Birth. 2005;32(4):299-305. [PubMed]

23. Mittiga C, Ettridge K, Martin K, Tucker G, Dubyna R, Catcheside B, et al. Sociodemographic correlates of smoking in pregnancy and antenatal-care attendance in Indigenous and non-Indigenous women in South Australia. Aust J Prim Health. 2015. [PubMed]

24. England LJ, Kim SY, Tomar SL, Ray CS, Gupta PC, Eissenberg T, et al. Non-cigarette tobacco use among women and adverse pregnancy outcomes. Acta Obstet Gynecol Scand. 2010;89(4):454-64. [PubMed]

25. Hossain MS, Kypri K, Rahman B, Arslan I, Akter S, Milton AH. Prevalence and correlates of smokeless tobacco consumption among married women in rural Bangladesh. PLoS One. 2014;9(1):e84470. [PubMed]

26. Bista B, Mehata S, Aryal KK, Thapa P, Pandey AR, Pandit A, et al. Socio-demographic Predictors of Tobacco Use among Women of Nepal: Evidence from Non Communicable
Disease Risk Factors STEPS Survey Nepal 2013. J Nepal Health Res Counc. 2015 Jan-Apr;13(29):14-9. [PubMed]

27. Spangler J, Song E, Pockey J, Sutfin EL, Reboussin BA, Wagoner K, et al. Correlates of smokeless tobacco use among first year college students. Health Educ J. 2014;73(6):693-701. [PubMed]

28. Vander Weg MW, DeBon M, Peterson AL, SherrillMittleman D, Klesges RC, Relyea GE. Prevalence and correlates of lifetime smokeless tobacco use in female military recruits. Nicotine Tob Res. 2005;7(3):431-41. [PubMed]

29. Walsh MM, Ellison J, Hilton JF, Chesney M, Ernster VL. Spit (smokeless) tobacco use by high school baseball athletes in California. Tob Control. 2000;9(suppl 2):ii32-i9. [PubMed]

30. Murukutla N, Turk T, Prasad C, Saradhi R, Kaur J, Gupta $\mathrm{S}$, et al. Results of a national mass media campaign in India to warn against the dangers of smokeless tobacco consumption. Tob Control. 2012; 21: 12-7. [PubMed]

31. Hovell MF, Zakarian JM, Matt GE, Hofstetter CR, Bernert JT, Pirkle J. Effect of counselling mothers on their children's exposure to environmental tobacco smoke: randomised controlled trial. BMJ. 2000;321(7257):33742. [PubMed]

32. Coffey SF, Lombardo TW. Effects of smokeless tobaccorelated sensory and behavioral cues on urge, affect, and stress. Exp Clin Psychopharmacol. 1998;6(4):406-18. [PubMed]

33. Ebbert JO, Patten CA, Schroeder DR. The Fagerström test for nicotine dependence-smokeless tobacco (FTND-ST). Addict Behav. 2006;31(9):1716-21. [PubMed] 